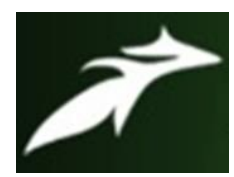

Pankaj Sharma et al, International Journal of Advances in Agricultural Science and Technology,

Vol.8 Issue.2, February-2021, pg. 33-38

ISSN: 2348-1358

Impact Factor: 6.057

NAAS Rating: 3.77

\title{
A Study on Identification of Indigenous Technology Knowledge (ITK) and its Utilization in Contemporary Modern Agriculture at Shajapur District of Madhya Pradesh
}

Mr. Pankaj Sharma ${ }^{1}$; Dr. Sandhya Choudhary ${ }^{2}$; Dr. S.K. Choudhary ${ }^{3}$; Dr. Deepak Kumar Verma ${ }^{4}$

${ }^{1}$ M.Sc. Students 2020, College of Agriculture, Indore

${ }^{2}$ Professor \& Head, Department of Extension \& Communication, College of Agriculture, Indore

${ }^{3}$ Contractual Teacher, Department of Extension \& Communication College of Agriculture, Indore

${ }^{4}$ Chief Scientist Dry land Farming Project, College of Agriculture, Indore

DOI: 10.47856/ijaast.2021.v08i2.005

\section{Abstract}

The ITK is an explicit or "codified" knowledge that is transmittable in formal, systematic language. On the other hand, ITK is a tacit knowledge of the local or indigenous people, which is personal, content-specific and therefore hard to formalize and communicate. Local or indigenous people acquire knowledge by actively creating and organizing their own experiences. Indigenous knowledge functions within the given socio-economic and spatial boundaries of the society and plays an active part in the culture of the population concerned, being preserved, communicated, and used by its members to serve some purpose in relation to productive activity within the society. Therefore, "A Study on Identification of Indigenous Technology Knowledge (ITK) and its Utilization in Contemporary Modern Agriculture at Shajapur District of Madhya Pradesh" with specific objective. The sample of the present study was selected by proportionate random sampling method 120 ITK users were selected randomly for this study through the KVK Shajapur, M.P. The finding regarding adoption behavior of ITK users in contemporary modern agriculture: the highest adoption observed in case of horticulture crop (mean score 2.20), followed by Sorghum (mean score 2.10), oil seed crops (mean score 2.06), soybean (mean score 1.99), maize (mean score 1.97), groundnut (mean score 1.95), wheat (mean score 1.92), weather forecasting (mean score 1.91), and pulses crops (mean score1.87). 


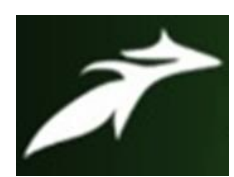

Pankaj Sharma et al, International Journal of Advances in Agricultural Science and Technology, Vol.8 Issue.2, February-2021, pg. 33-38

ISSN: 2348-1358

Impact Factor: 6.057

NAAS Rating: 3.77

\section{Introduction-}

Indigenous knowledge can play a key role in the design of sustainable agricultural systems, increasing the likelihood that rural populations will accept, develop, and maintain innovations and interventions. It can be defined as the sum of experience and knowledge of a given ethnic group that forms the basis for decision-making in the face of familiar and unfamiliar problems and challenges. Farmers of agrarian, as well as industrialized, societies have sophisticated ways of looking at the world.

The ITK is an explicit or "codified" knowledge that is transmittable in formal, systematic language. On the other hand, ITK is a tacit knowledge of the local or indigenous people, which is personal, content-specific and therefore hard to formalize and communicate. Local or indigenous people acquire knowledge by actively creating and organizing their own experiences. Thus, the (traditional) knowledge that can be expressed in words and numbers represents only the "tip of the iceberg" of the entire body of knowledge possessed by indigenous people.

Accessing to indigenous knowledge would enforce primary foundation of sustainable development. On the on hand, indigenous knowledge is production of empirical learning process and at the other hand is test and error of few thousand years of one society in relation to its environment. It is obvious that this knowledge represents human's interaction with nature and displays features of climate and specifications of vegetarian and animal nature of one region and more important, it displays their interactions with human.

\section{Objective-}

To study the documentation and classification of identified indigenous technology knowledge (ITK) perceived by ITK users.

\section{Review Literature-}

Sharma (2003) reported that the indigenous practices being followed by some of the farmers may not be scientifically hundred per cent correct but since adopted by the farmers over generations, the way has some bass which need to be systematically evaluated by scientists. The objective of study was to provide Feedback to the scientist sabot practice being adopted by the farmers of operational area. If some of the indigenous practices prove scientifically incorrect, the farmers should be advised accordingly.

Nirban (2006) reported that slightly less than two third (64.78 per cent) of the respondents had 'medium' adoption of the IRCPs, more than one fifth (22.54percent) had adopted the IRCPs to 'low' 


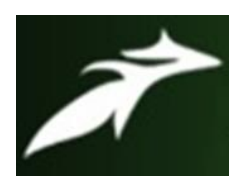

Pankaj Sharma et al, International Journal of Advances in Agricultural Science and Technology, Vol.8 Issue.2, February-2021, pg. 33-38

ISSN: 2348-1358

Impact Factor: 6.057

NAAS Rating: 3.77

degree, while12.68 percent had 'high' adoption of IRCPs. The mean score of adoption of IRCPs was 15.31whichindicated'medium' adoption.

Reddy (2006) reported that more number of vegetable growers were notice din medium adopter category of IPM practices in tomato (63.33percent) and cabbage crop (59.17per cent).

Maravi (2009) reported that majority of the respondents (46.67per cent) had medium level of adoption regarding to ITK in agriculture, 36.67 per cent low and 16.66 per cent of them high level of adoption of ITK in agriculture. Hence, it may be concluded that the level of respondents about adoption of ITK was medium to low.

Lakra et al. (2010) reported that the extent of adoption of various indigenous agricultural practices in Jharkhand. Study revealed that 90.00 per cent of the respondent adopted soil management practices followed by weed management adopted by 87.00 per cent with use of indigenous agricultural practices.

\section{Material \& Methods -}

The present study was confined in Shajapur district of Madhya Pradesh, agricultural season 2018- 2019. For this study 205 ITK users existed in the selected 9 villages on the information from KVK. Out of this list, 120 ITK users were selected randomly on this study. The data was analyzed using appropriate statistical tools.

According to Rogers (1983) adoption has been operationalzed as whether an individual practiced each of the selected Indigenous Technical Knowledge items over a period of time. The respondents were narrated about the selected Indigenous Technical Knowledge items one by one, each item enquiring whether they adopted completely or partially or not adopted the practice in the previous years. Each respondent was asked for his adoption in the crops grown by him. A single farmer was assessed for 7 items in agriculture on an average for his adoption.

The scores of all the Indigenous Technical Knowledge were added up for each respondent to arrive at total adoption score and the adoption index was worked out by using the following formula:

Score obtained by the individual respondent

Adoption Index $=$ X 100

Total maximum score of all items applicable 


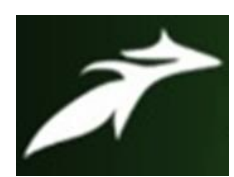

Pankaj Sharma et al, International Journal of Advances in Agricultural Science and Technology, Vol.8 Issue.2, February-2021, pg. 33-38

ISSN: 2348-1358

Impact Factor: 6.057

NAAS Rating: 3.77

The adoption index was used to find out the relationship between adoption and selected independent variables. Based on adoption coefficient values, the extent of adoption of Indigenous Technical Knowledge of different crops were grouped as low, medium and high based on mean and standard deviation.

\section{Result \& Discussion}

Table: Categorization of Indigenous Technical Knowledge items in Agriculture

\begin{tabular}{|c|l|c|c|c|}
\hline \multirow{2}{*}{ S. No. } & \multicolumn{1}{|c|}{ Statement } & \multicolumn{2}{c|}{ Indigenous technology knowledge } \\
\cline { 3 - 5 } & & Low & Medium & High \\
\hline 1. & Soil management & $44(36.67)$ & $59(49.17)$ & $17(14.16)$ \\
\hline 2. & Variety seed and their & $53(44.17)$ & $49(40.83)$ & $18(15.00)$ \\
\hline 3. & Seed treatment & $63(52.50)$ & $29(24.17)$ & $28(23.33)$ \\
\hline 4. & Manure and soil fertility & $59(49.17)$ & $34(28.33)$ & $27(22.50)$ \\
\hline 5. & Weed management & $61(50.83)$ & $39(32.50)$ & $20(16.67)$ \\
\hline 6. & Insect control & $32(26.67)$ & $53(44.17)$ & $35(29.16)$ \\
\hline 7. & Disease and pest & $41(34.17)$ & $56(46.67)$ & $23(19.16)$ \\
\hline 8. & Other practices and & $55(45.83)$ & $43(35.83)$ & $22(18.33)$ \\
\hline & management & $\mathbf{5 1 ( 4 2 . 5 0 )}$ & $\mathbf{4 5 ( 3 7 . 5 0 )}$ & $\mathbf{2 4 ( 2 0 . 0 0 )}$ \\
\hline
\end{tabular}

\section{Soil management:}

It could be observed that 49.17 per cent of respondent had medium knowledge 36.67 per cent of respondent had low knowledge whereas, only 14.16 per cent respondent had high knowledge related to soil management practices.

\section{Variety seed and their management:}

It could be observed that majority 44.17 per cent of responsive had low knowledge, 40.83 per cent had medium knowledge whereas, only 15.00 per cent had high knowledge related to Variety seed and their management.

\section{Seed treatment:}

Majority 52.50 per cent had low knowledge, 24.17 per cent had medium knowledge whereas, only 23.33 per cent had high knowledge related to seed treatment. 


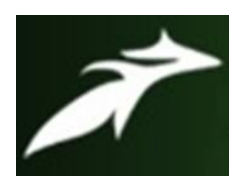

Pankaj Sharma et al, International Journal of Advances in Agricultural Science and Technology, Vol.8 Issue.2, February-2021, pg. 33-38

ISSN: 2348-1358

Impact Factor: 6.057

NAAS Rating: 3.77

\section{Manure and soil fertility:}

Majority 49.17 per cent had low knowledge, 28.33 per cent had medium knowledge whereas, only22.50percenthadbroadknowledgerelatedtoManureand soil fertility.

\section{Weed management:}

Majority 50.83 per cent had reduced knowledge, 32.50 per cent had medium knowledge whereas, only 16.67 per cent had high knowledge related to weed management.

\section{Insect control:}

Majority 44.17 per cent had intermediate knowledge, 29.16 per cent had broad knowledge whereas, 26.67 per cent had low knowledge related to insect control.

Disease and pest control:

Majority46.67 per cent had average knowledge, 34.17 per cent had low-level knowledge whereas, only19.16percenthadbroadknowledgerelatedtodiseaseand pest control.

\section{Other practices and management:}

Majority 45.83 per cent had low-level knowledge, 35.83 per cent had moderate knowledge whereas, only 18.33 per cent had broad high knowledge related to other practices and management.

\section{Overall}

Majority 42.50 per cent had low-level knowledge, 37.50 per cent had medium knowledge whereas, only 20.00 per cent had high knowledge in related to overall agricultural practice and management.

\section{Adoption behavior of ITK users in contemporary modern agriculture}

Table 4.13: ITK users in contemporary modern agriculture

\begin{tabular}{|c|l|c|c|c|c|c|}
\hline \multirow{2}{*}{ S. No. } & \multicolumn{1}{|c|}{ Type of crop } & \multicolumn{3}{|c|}{$\begin{array}{c}\text { Adoption behavior of ITK } \\
\text { users }\end{array}$} & Total score & Mean \\
& & & \multicolumn{3}{|c|}{ score } \\
\cline { 3 - 6 } & & Low & Medium & High & \\
\hline 1. & Maize & 20 & 83 & 17 & 237 & 1.97 \\
\hline 2. & Soyabean & 21 & 79 & 20 & 239 & 1.99 \\
\hline 3. & Horticulture crop & 13 & 69 & 38 & 265 & 2.20 \\
\hline 4. & Groundnut & 23 & 79 & 18 & 235 & 1.95 \\
\hline 5. & Wheat & 31 & 67 & 22 & 231 & 1.92 \\
\hline
\end{tabular}




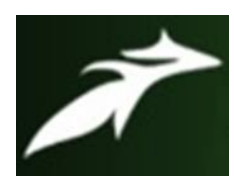

Pankaj Sharma et al, International Journal of Advances in Agricultural Science and Technology, Vol.8 Issue.2, February-2021, pg. 33-38

ISSN: 2348-1358

Impact Factor: 6.057

NAAS Rating: 3.77

\begin{tabular}{|c|l|c|c|c|c|c|}
\hline 6. & Pulses & $\mathbf{2 6}$ & $\mathbf{8 3}$ & $\mathbf{1 1}$ & $\mathbf{2 2 5}$ & $\mathbf{1 . 8 7}$ \\
\hline 7. & Oil seed & $\mathbf{1 8}$ & $\mathbf{7 6}$ & $\mathbf{2 6}$ & $\mathbf{2 4 8}$ & $\mathbf{2 . 0 6}$ \\
\hline 8. & Sorghum & $\mathbf{2 2}$ & $\mathbf{6 3}$ & $\mathbf{3 5}$ & $\mathbf{2 5 3}$ & $\mathbf{2 . 1 0}$ \\
\hline 9. & Weather forecasting & $\mathbf{3 7}$ & $\mathbf{5 6}$ & $\mathbf{2 7}$ & $\mathbf{2 3 0}$ & $\mathbf{1 . 9 1}$ \\
\hline
\end{tabular}

The data presented in the table indicates the cultivated crops of respondents under indigenous technology knowledge that they realized the Adoption behavior of ITK use in contemporary modern agriculture. The highest adoption is found in horticulture crop (mean score 2.20), fall out by Sorghum (mean score2.10), oil seed crops (mean score 2.06), soyabean (mean score 1.99), maize (mean score 1.97), groundnut (mean score 1.95), wheat (mean score 1.92), weather forecasting (mean score 1.91), and pulses crops (mean score1.87).

\section{References}

[1]. Lakra, V.; Singh, M. K.; Sinha, R. and Kudada, N. (2010). Indigenous technology of tribal farmers in Jharkhand. Indian Journal of traditional Knowledge. 9(2):261-263.

[2]. Maravi, M.S. (2009). Depiction of Indigenous Technological Knowledge (I.T.K) in agricultural aspects prevailing in Gwalior region of Madhya Pradesh.M.Sc(Ag.) Thesis Submitted to Jawaharlal Nehru Krishi Vishwa Vidyalaya,Jabalpur.

[3]. Nirban, A. A. (2006). A study on indigenous technical knowledge about rice Cultivation and bovine health management practices in konkan region of Maharashtra, College of agriculture, Dhadwad.

[4]. Reddy, V.S. (2006). Knowledge and adoption of integrated pest management practices among vegetable growers of Gadag distrsict in North Karnataka.M.Sc. (Ag.)Thesis submitted to the University of Agricultural Sciences, Dharwad.

[5]. Sharma, P.N. (2003). Use of indigenous knowledge in agriculture Indian Journal of Extension Education. 21(1\&2):13-20. 